\title{
Effect of Diallyl Disulphide (DADS) on Gluconeogenesis: A Study in Isolated Alloxan Induced Diabetic Liver
}

\author{
Prashanth kumar Goudappala ${ }^{1,2}$, Ethirajan Sukumar', C V Yogaraje-Gowda ${ }^{3}$, Kashinath RT ${ }^{4, *}$
}

\section{Prashanth kumar Goudappala1,2, Ethirajan Sukumar', C V Yogaraje- Gowda ${ }^{3}$, Kashinath $\mathrm{RT}^{4, * *}$}

'Department of Research and

Development, Saveetha Institute of Medical and Technical Science (Deemed University),

Thandalam, Chennai-602 105, INDIA.

${ }^{2}$ Department of Biochemistry, Subbaiah

Institute of Medical Sciences, Purle,

Shivamogga-577 222, INDIA.

${ }^{3}$ Department of Biochemistry, Bangalore

Medical College, Bangalore, INDIA.

${ }^{4}$ Department of Research and

Development, Subbaiah Institute of

Medical Sciences, Purle, Shivamogga-577

222, INDIA.

\section{Correspondence}

Kashinath RT

Department of Research and

Development Subbaiah Institute

of Medical Sciences, Purle, Nh-13,

Shivamogga-577222, INDIA

Phone no: +91-9886517959

E-mail: rsearch.smc@gmail.com

drkashinath_1945@yahoo.co.in

History

- Submission Date: 22-02-2019;

- Review completed: 03-04-2019;

- Accepted Date: 28-04-2019.

DOI : 10.5530/pj.2019.11.123

Article Available online

http://www.phcogj.com/v11/i4

Copyright

(C) 2019 Phcogj.Com. This is an openaccess article distributed under the terms of the Creative Commons Attribution 4.0 International license.

\begin{abstract}
Background: Coordinated regulation between cellular glucose uptake and endogenous glucose production is indispensable for maintenance of constant blood glucose concentrations. Liver contributes significantly by altering levels of hepatic glucose release, through controlling gluconeogenesis. Objective: To assess effect of Diallyldisulphide on hepatic gluconeogenesis by assessing gluconeogenic substrates and activity of regulatory enzyme glucose-6-phosphatase and to compare the Diallyldisulphide effect on gluconeogenesis with Metformin. Methodology: Wistar albino rats were categorized into four groups; group Inormal control. Group II, III and IV rats were administered single intraperitoneal injection of alloxan monohydrate $150 \mathrm{mg} / \mathrm{kg}$ body weight. Rats were maintained on rat diet and water adlibitum for 30 days. On 31 st day rats were sacrificed and procured liver tissues. Each liver tissue cut into small slices and group-III and group-IV liver tissues were separately incubated with Diallyldisulphide $4 \mathrm{mg} / \mathrm{g}$ liver tissues and Metformin $4 \mathrm{mg} / \mathrm{g}$ liver tissues for 60 minutes at $37^{\circ} \mathrm{C}$. The total amino acids and total keto acids levels were estimated after exposure. And post exposure effect on activity of glucose -6-phoshatase and transaminases were also estimated. Results: Alloxan induced diabetes resulted significant raise in total amino acids, total ketoacids, glucose -6-phosphatase and transaminases activities. Whereas incubation of liver tissues with diallyldisulphide significantly reduced total amino acids, total ketoacids, glucose-6-phosphatase, transaminases activities and ratio of total amino acids and ketoacids as compared to diabetic control rat liver tissues.

Conclusion: Study suggested that diallyldisulphide suppressed gluconeogenesis as liver glucose-6-phosphatase activity is significantly decreased and precursors for gluconeogenesis were significantly reduced. Suggesting Diallyldisulphide has role in gluconeogenesis and can hold potentials for glucose homeostasis.
\end{abstract}

Key words: Alloxan, Diallyldisulphide, Diabetes mellitus, Total amino acid, Total keto acid, Gluconeogenesis, Glucose-6-phosphatase.

\section{INTRODUCTION}

Diabetes mellitus (DM) is chronic metabolic disorder characterized by hyperglycemia due to subnormal functioning of insulin. ${ }^{1,2}$ Diabetic hyperglycemia if not properly regulated may lead to life threatening micro and macro vascular complications including retinopathy, neuropathy and nephropathy. ${ }^{3,4}$ Many herbal preparations specifically extracts of garlic (Allium Sativum Linn.), have been claimed useful in controlling glycemic status in Diabetes Mellitus (DM). ${ }^{5-10}$ The important sulfur compound of garlic oil, Diallyldisulphide (DADS), has been proved to be beneficial in DM. ${ }^{11,12}$ Though it is known DADS may enhance insulin action as well as may favor insulin half-life but the mechanism of DADS in regulating glucose metabolism in DM is obscure. ${ }^{11,13}$

Gluconeogenesis, a process of glucose production from non carbohydrate precursors, is normally very active in diabetes mellitus due to lowered insulin action as insulin is known to suppress tissue proteolysis as well as gluconeogenesis. Apart from lactate and glycerol, the gluconeogenic aminoacids like alanine, aspartate, glutamate along with their corresponding a-keto derivates, pyruvate, oxaloacetate, $\alpha$-keto glutarate promotes gluconeogenesis. ${ }^{14,15}$ Diabetic conditions as the tissue proteolysis suppression action of insulin is minimum due to lowered action of insulin as observed in Type-2 DM. Hence more amino acids and their corresponding $\alpha$-keto acids are channeled through gluconeogenic pathway inducing more glucose production resulting in gluconeogenesis induced hyperglycemia. There are no simpler methods, apart from tracer techniques, to assess gluconeogenic status in diabetes mellitus. A simple method to assess gluconeogenic precursors and gluconeogenic enzymes looks promising. Hence a study was undertaken to establish the role of DADS on gluconeogenesis in alloxan diabetic rat liver slices by estimating the liver tissue levels of total amino acids (TAA), total keto acids (TKA) and the action of glucose-6-phophatase in DADS exposed alloxan diabetic liver slices.

\section{MATERIALS AND METHODS}

\section{Chemicals}

Diallyldisulphide, Metformin and Alloxan monohydrate were obtained from Sigma Aldrich

Cite this article: Goudappala PK, Sukumar E, Yogaraje-Gowda CV, Kashinath RT. Effect of Diallyl Disulphide (DADS) on Gluconeogenesis: A Study in Isolated Alloxan Induced Diabetic Liver. Pharmacog J. 2019;11(4):777-81. 
Chemicals (St. Louis, U.S.A.) and the remaining chemicals used were of analytical grade.

\section{Experimental animals}

Healthy male Wistar rats weighing $200 \pm 50 \mathrm{~g}$ body weight were randomly selected from animal house, Basaveshwara Medical College and Hospital, Chitradurga, India. Animals were maintained at standard laboratory conditions 12 hours day-night cycle at temperature of $22 \pm$ $2^{\circ} \mathrm{C}$. The experiments were conducted as per the guidelines of CPCSEA under the supervision of Institutional Animal Ethics Committee (BMCH/IAEC/04 Biochem/2015).

\section{Animal groups}

Wistar albino rats were categorized into four different groups; group I served as normal control. Group II, III and IV overnight fasted rats were administered with single intraperitoneal injection of freshly prepared Alloxan monohydrate $150 \mathrm{mg} / \mathrm{kg}$ body weight. The onset of diabetes was monitored 48 hours after Alloxan injection by using urine strips (Mission Urine strips) and the animals that tested positive for glucose for 3 consecutive days were considered as diabetic rats employed in the present study. Rats were maintained on rat diet and water ad libitum for 30 consecutive days. On $31^{\text {st }}$ day all the rats were sacrificed and procured liver tissues. Each liver tissue was cut into small slices, group I and group II liver tissues were suspended in cold phosphate buffer saline pH 7.4. Group III and group- IV liver tissues were separately incubated with Diallyldisulphide $4 \mathrm{mg}$ per gram liver tissues and Metformin $4 \mathrm{mg}$ per gram liver tissues for 60 minutes at $37^{0} \mathrm{C}^{18,19}$. Post exposure effect on activity of glucose - 6-phoshatase, total amino acids, total keto acids and transaminases were also estimated using standard protocol.

\section{Estimation of total amino acids (TAA) and total ketoacids (TKA)}

Pre-incubation study- Liver slice weighing $0.5 \mathrm{~g}$ from every rat in each group were separately taken in incubation tubes. To all the tubes $1 \mathrm{ml}$ phosphate buffer saline (PBS) pH 7.4 was added, followed by $6.5 \mathrm{ml}$ double distilled water (DDW) and $1.0 \mathrm{ml}$ sodium Tungstate (10\%) as well as $1.0 \mathrm{ml} 2 / 3 \mathrm{~N}$ Sulfuric acid were added, mixed well. To the tubes containing liver slices of reference standard group, added $10 \mu \mathrm{l}$ Metformin ( $4 \mathrm{mg} / \mathrm{g}$ liver) and to the treatment group, $10 \mu \mathrm{l}$ of DADS ( $4 \mathrm{mg} / \mathrm{g}$ liver $)^{20,21}$ were added. Tubes were allowed to stand at room temperature for 15 minutes for proteins to precipitate. After that the tubes were thoroughly homogenized using Remi homogenizer for 6 minutes and were later centrifuged at $3500 \mathrm{rpm}$ for 8 minutes. The clear supernatant was used for estimation TAA and TKA. Total amino acids were estimated by the method of Folin ${ }^{22}$ where amino acids upon reaction with $\beta$-naphthoquinone-4-sulphonate in alkaline media produces a brown colour complex. The intensity of which is measured in a spectrophotometer at $480 \mathrm{~nm}$ wavelength. Keto acids present in Tungstate filtrate treated with Dinitro phenyl hydrazine (DNPH) produces corresponding hydrazones which react with strong alkali to form red colour which is measured at $540 \mathrm{~nm}$ in spectrophotometer. These values were taken as pre-incubation levels of TAA and TKA. ${ }^{22,23}$

Post-incubation study: Liver slice weighing $0.5 \mathrm{~g}$ of every rat of each group were separately taken in incubation tubes. Added $1 \mathrm{ml}$ phosphate buffer saline (PBS) pH 7.4 to all the test labeled tubes. Followed by 2 $\mathrm{mg}$ DADS as $10 \mu \mathrm{l}$ normal saline solution to Group III and $2 \mathrm{mg}$ of Metformin as $10 \mu \mathrm{l}$ normal saline solution to Group IV test tubes respectively. The tubes were incubated for 60 minutes at $37^{\circ} \mathrm{C}$ in a thermostatically regulated water bath. After incubation $6.5 \mathrm{ml}$ double distilled water, $1.0 \mathrm{~mL}$ of sodium Tungstate (10\%) followed by 1.0 $\mathrm{ml} 2 / 3 \mathrm{~N}$ Sulfuric acid were added. The contents of the tubes were mixed well and were allowed to stand for 15 minutes for proteins to precipitate. Then the tubes were thoroughly homogenized using Remi homogenizer for 6 minutes and the clear supernatant was used for estimation of TAA ${ }^{22}$ and TKA. ${ }^{23}$ These values were considered as postincubation levels. These values were taken as pre-incubation levels of TAA and TKA. ${ }^{22,23}$ The differences between the post-incubation and pre-incubation values gives the total amount amino acid and keto acids produced during incubation period.

\section{Estimation of glucose- 6 phosphatase}

Glucose- 6 phosphatase was estimated by the phosphate release method. ${ }^{24,25} 0.5 \mathrm{~g}$ of liver tissue of each group was homogenized in $6 \mathrm{ml}$ of double distilled water (DDW) and $0.1 \mathrm{ml}$ of homogenate of each liver tissue of each group was separately incubated with $0.2 \mathrm{M}$ glucose- 6 phosphate in $0.1 \mathrm{M}$ citrate buffer (pH6.3) for 30 minutes and the released inorganic phosphate was measured as explained originally by Fiske and Subbarow method. ${ }^{25}$

\section{Estimation of transaminases (AST and ALT)}

The same supernatant of post incubation studies were employed for estimation transaminases (AST and ALT) ${ }^{26}$ levels were estimated by the colorimetric method of Reitman and Frankel separately in each liver homogenate of all the four groups.

\section{Statistical analysis}

Results were expressed as their Mean \pm SEM. The statistical significance were assessed using Microsoft Excel 2007 (Redmond, Washington, USA) and SPSS package (Version16.0, IBM Corporation, New York, USA). The data were compared with diabetic control group using oneway ANOVA followed by Dunnett's multiple comparison test. P-values $<0.05$ were considered as statistically significant.

\section{RESULTS}

Single intraperitoneal injection of Alloxan readily induced diabetic in rats, which is confirmed from urine test. Biochemical investigations showed a significant increase in the total amino acids and total keto acids in diabetic control liver homogenate as compared to normal control $(\mathrm{p}<0.01)$. And there was significant increase in the glucose- 6 phosphatase and transaminase (AST and ALT) activities as compared to normal control liver homogenate $(\mathrm{p}<0.01)$. Whereas the test drug DADS and Metformin significantly attenuated the raise in the total amino acids, total ketoacids and glucose- 6 phosphatase and transaminase activities as compared to diabetic control. The DADS results were comparable with that of Metformin treatment (Tables 1 and 2).

It is evident from the figures that the ratios of TAA/TKA and $(\mathrm{TAA}+\mathrm{TKA}) /(\mathrm{AST}+\mathrm{ALT})$ are significantly elevated in diabetic control liver homogenate as compared to normal control, whereas DADS and Metformin incubation has shown significant reduction in the ratios as compared to diabetic control $(p<0.01)$. The DADS results were comparable with that of Metformin treatment (Figures 1 and 2).

Table 1: Effect of DADS on the levels of total amino acids (TAA) and total keto acids (TKA) in Alloxan induced diabetic rats.

\begin{tabular}{|c|c|c|c|}
\hline Groups & Treatments & $\begin{array}{c}\text { Total amino acids in } \\
\mathrm{mg} / \mathrm{g} \text { liver tissue }\end{array}$ & $\begin{array}{l}\text { Total keto acids in } \\
\mathrm{mg} / \mathrm{g} \text { liver tissue }\end{array}$ \\
\hline I & Control & $2.95 \pm 0.02$ & $0.07 \pm 0.007$ \\
\hline II & Diabetic & $9.75 \pm 0.34^{\circledR}$ & $0.14 \pm 0.004^{\circledR}$ \\
\hline III & $\begin{aligned} & \text { Diabetic } \\
&+ \text { Metformin }\end{aligned}$ & $4.10 \pm 0.24^{\# \#}$ & $0.20 \pm 0.026^{\#}$ \\
\hline IV & Diabetic +DADS & $4.51 \pm 0.27^{\# \#}$ & $0.23 \pm 0.010^{\# \#}$ \\
\hline
\end{tabular}

Data represented in Mean $\pm \mathrm{SEM},{ }^{*} p<0.05,{ }^{* *} p<0.01$, @- in comparison to control; \# - in comparison to diabetic. 
Table 2: Effect of DADS on AST and ALT in Alloxan induced diabetic rats.

\begin{tabular}{cccc}
\hline Groups & Treatments & AST (IU) & ALT (IU) \\
\hline I & Control & $71.26 \pm 0.32$ & $73.03 \pm 0.32$ \\
II & Diabetic & $79.27 \pm 0.21^{\complement @}$ & $82.10 \pm 0.21^{\complement}$ \\
III & Diabetic +Metformin & $76.33 \pm 0.91^{* *}$ & $74.5 \pm 0.98^{* *}$ \\
IV & Diabetic +DADS & $74.05 \pm 0.58^{* *}$ & $76.83 \pm 0.58^{* \#}$ \\
\hline
\end{tabular}

Data represented in Mean \pm SEM, ${ }^{* *} p<0.01$, @- in comparison to control; \# - in comparison to diabetic.

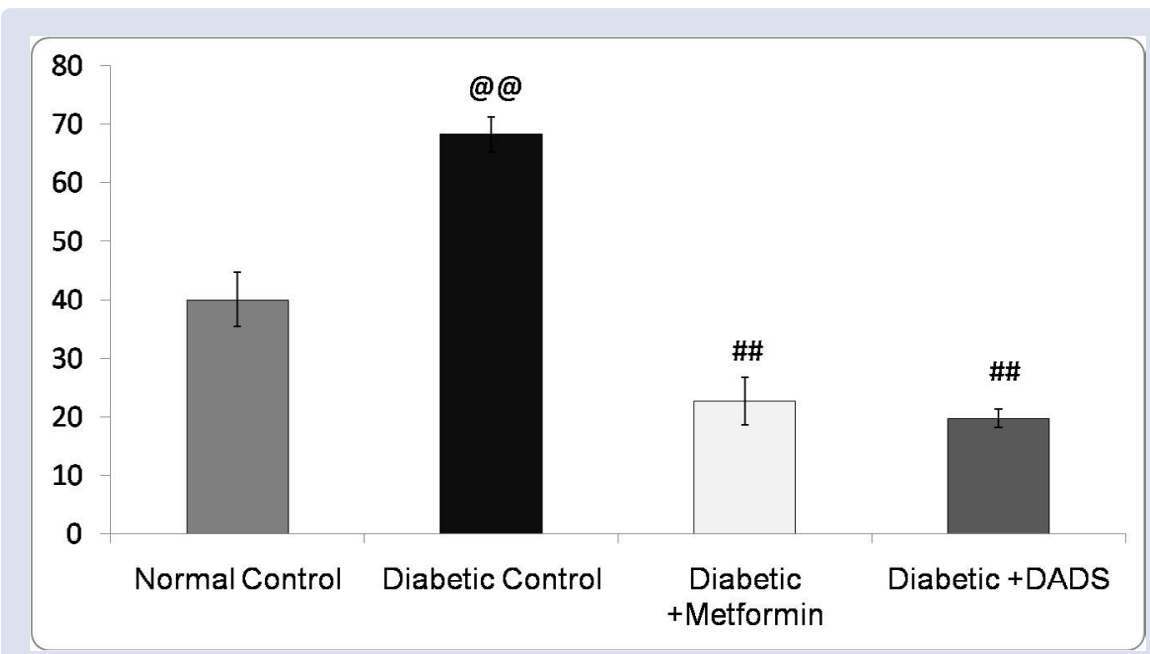

Figure 1: Effect of DADS on the Ratio of total amino acid and total keto acid . Data represented in Mean \pm SEM, ${ }^{* *} p<0.01$, @- in comparison to normal control; \# - in comparison to diabetic control.

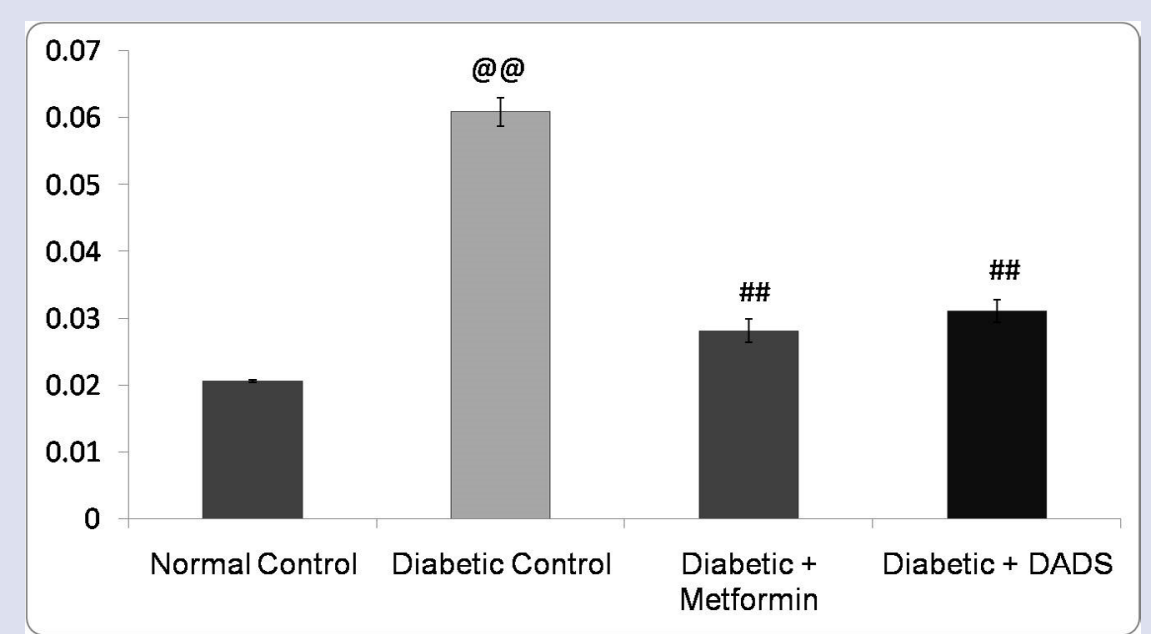

Figure 2: Effect of DADS on the ratio of (TAA+TKA)/ (AST+ALT). Data represented in Mean \pm SEM, ${ }^{* *} p<0.01$, @- in comparison to normal control; \# - in comparison to diabetic control.

\section{DISCUSSION}

Gluconeogenesis, a pathway for the production of glucose from noncarbohydrate compounds, is one of the principle in vivo procedures for addition of glucose hence to maintain glucose homeostasis. The primary stimulus for gluconeogenesis may be lowered intra cellular glucose levels. It is known that insulin is the lone hormone suppressing gluconeogenesis and it acts predominantly by suppressing the expression of the genes for the key gluconeogenic enzymes involving glucose-6-phosphatase $\mathrm{e}^{27}$ and as the insulin action is sub normal in Type-2 DM, hence gluconeogenesis process becomes a significant for increased blood glucose levels leading to hyperglycemia. A simple procedure (non-tracer procedures) becomes essential in order to check gluconeogenesis induced hyperglycemia in DM.

In this study liver tissue levels of total amino acids, total keto acids and the activity of glucose- 6 phosphatase have been assessed in DADS exposed alloxan diabetic liver slices ( $4 \mathrm{mg} / \mathrm{g}$ liver). The effects of DADS on these parameters were compared with Metformin, a standard anti diabetic drug by exposing alloxan diabetic liver slices to Metformin ( $4 \mathrm{mg} / \mathrm{g}$ liver). The results show a significant increase in TAA, TKA as well as Glucose-6-Phosphatase activity in diabetic control as compared to normal control. Establishing lowered insulin action in alloxan diabetic liver is responsible for the raise in TAA, TKA levels which 
are channeled through gluconeogenesis as there is a significant raise in activities of liver glucose-6-phosphatase. Whereas the TAA, TKA levels and glucose-6-Phosphatase activity are significantly lowered in DADS and Metformin treatment as compared to diabetic control. Indicating Metformin and DADS incubation has antiproteolytic as well as antigluconeogenic effects suggesting these compounds may control hepatic gluconeogenesis in alloxan diabetic rat liver. The ratios of liver TAA/TKA and liver TAA+TKA/ AST+ALT may be better marker for hepatic gluconeogenic rate in Alloxan diabetic rat, as they gives a rough estimation of utility of gluconeogenic precursors, amino acids and keto acids. Hence the level of these ratios becomes significant in assessing hepatic gluconeogenic status in Alloxan diabetic rats. The levels of these ratios are significantly elevated in diabetic control indicating increased flow of gluconeogenic precursors to gluconeogenesis. This is further evidenced by a significant fall in the levels of these ratios in DADS and Metformin treatment compared to diabetic control indicates that the DADS a comparable as well as a better anti-gluconeogenic effect in Alloxan diabetic liver.

It has been evident from earlier research that Metformin an antidiabetic drug, do regulate the hepatic gluconeogenesis by suppressing glucose- 6 phosphatase action through a cyclic AMP mediated signaling transduction pathway involving cAMP-response element-binding protein (CBP/CREBP) signaling route. ${ }^{28-30}$ It is evident from the present studies the glucose -6-Phosphatase levels are significantly lowered in DADS and Metformin suggesting DADS might have induced a reduction in hepatic gluconeogenesis similar to Metformin.

It is known that two closely situated cysteine residues in CBP are responsible for binding of CBP to DNA and further to initiate its action at this transcription level. ${ }^{31,32}$ DADS, is a low molecular wt. lipid soluble disulphide, similar to any other disulphide might have undergone a sulfhydryl reaction with these signaling molecules (CBP/CREB) and blocked its action, hence decreasing the formation of glucose-6phosphatase thereby suppressing gluconeogenesis. ${ }^{33,34}$

\section{CONCLUSION}

Based on the present study results we could say DADS can exhibit a significant decrease in hepatic gluconeogenesis by lowering flow of gluconeogenic amino acids and keto acids and this action is well comparable with Metformin the known anti diabetic drug suggesting DADS is a potent hepatic gluconeogenic modulator.

\section{SOURCE(S) OF SUPPORT}

Self.

\section{CONFLICTING INTEREST}

The authors have no conflicts of interest.

\section{ABBREVIATIONS}

DM: Diabetes Mellitus; DADS: Diallyldisulphide; TAA: Total Amino Acids; TKA: Total Keto Acids; PBS: Phosphate Buffer Saline; DDW: Double Distilled Water; DNPH: Dinitro Phenyl Hydrazine; AST: Aspartate Transaminase; ALT: Alanine Transaminase; CBP/CREBP: cAMP-Response Element-Binding Protein.

\section{REFERENCES}

1. American Diabetes Association. Diagnosis and classification of diabetes mellitus. Diabetes Care. 2010;33:62-9.

2. Altan VM. The pharmacology of diabetic complications. Curr Med Chem. 2003; 10:1317-27.

3. American Diabetes Association. Diagnosis and classification of diabetes mellitus. Diabetes Care. 2014;37:81-90.

4. Fowler MJ. Microvascular and macrovascular complications of diabetes. Clin Diab. 2008;26:77-82.
5. El-Demerdash FM, Yousef MI, El-Naga NA. Biochemical study on the hypoglycemic effects of onion and garlic in alloxan-induced diabetic rats. Food and Chem Toxicol. 2005;43:57-63.

6. Augusti KT. Therapeutic values of onion (Allium cepa L.) and garlic (Allium sativum L.). Ind J Exp Biol. 1996;34:634-40.

7. Thomson M, Al-Amin ZM, Al-Qattan KK, Shaban LH, Ali M. Anti-diabetic and hypolipidaemic properties of garlic (Allium sativum) in streptozotocin-induced diabetic rats. Int J Diab \& Met. 2007;15:108-15.

8. Sheela CG, Augusti KT. Antidiabetic effects of S-allyl cysteine sulphoxide isolated from garlic Allium sativum Linn. Ind J Exp biol. 1992;30:523-6.

9. Aggarwal KC. Therapeutic uses of garlic. Ind J Exp Biol. 1996;11:239-41.

10. Kumari K, Mathew BC, Augusti KT. Antidiabetic and hypolipidemic effects of S-methyl cysteine sulfoxide isolated from Allium cepa Linn. Ind J Bioch Biophy 1995;32:49-54.

11. Mathew PT, Augusti KT. Studies on the effect of allicin (diallyl disulphide-oxide) on alloxan diabetes. I. Hypoglycaemic action and enhancement of serum insulin effect and glycogen synthesis. Ind J Bioch Biophy. 1973;10:209-12.

12. Sambu NK, Kashinath RT, Ambekar JG. Effect of diallyl disulphide on diabetes induced dyslipidemia in male albino rats. J Clin Diagn Reas. 2015;9:01.

13. Augusti KT. Studies on the effects of a hypoglycemic principle from Allium Cepa Linn. The Ind J Med Resea.1973;61:1066-71.

14. Gerich, JE, Meyer C, Woerle HJ, Stumvoll M. Renal gluconeogenesis: its importance in human glucose homeostasis. Diabetes Care. 2001;24:382-91.

15. Garrett RH, Grisham CM. Principles of biochemistry: with a human focus Orlando, Florida: Harcourt College Publishers; 2002.

16. Szkudelski T. The mechanism of alloxan and streptozotocin action in B cells of the rat pancreas. Phy Research. 2001;50:537-46.

17. Chougale AD, Panaskar SN, Gurao PM, Arvindekar AU. Optimization of alloxan dose is essential to induce stable diabetes for prolonged period. Asian J Biochem. 2007;2:402-8.

18. Renold AE, Teng CT, Nesbett FB, Hastings AB. Studies on carbohydrate metabolism in rat liver slices. 2. The effect of fasting and of hormonal deficiencies. J Biol Chem. 1953;204:533-46.

19. Vickram, Divya D, Raiker VG, Kashinath RT. Effect of thiopropanol on glucose utilization in alloxan diabetic rat liver. Global Journal of Medical Research. 2011;11:25-30.

20. Goudappala P, Sukumar E, Kashinath RT. Influence of diallyldisulphide on glycogen breakdown in alloxan diabetic liver. IOSR Journal of Dental and Medical Sciences. 2017; 16:30-2.

21. Goudappala P, Sukumar E, Kashinath RT. Effect of diallyl disulphide on glucose utilization in isolated alloxan diabetic liver. Biomed Research. 2018;29:3207-12.

22. Varley H. Non-protein nitrogen. In: practical clinical biochemistry. 4th ed. CBS Publishers, New Delhi. 1988;210-2.

23. Varley H. Enzymes. In: practical clinical biochemistry. 4th ed. CBS Publishers, New Delhi. 1988;287-97.

24. Ashmore J, Hastings AB, Nesbett FB. The effect of diabetes and fasting on liver glucose-6-phosphatase. Proceedings of the National Academy of Sciences. 1954;40:673-8.

25. Fiske $\mathrm{CH}$, Subbarow $\mathrm{Y}$. The colorimetric determination of phosphorus. J bio Chem. 1925;66(2):375-400

26. Reitman S, Frankel S. A colorimetric method for the determination of serum glutamic oxalacetic and glutamic pyruvic transaminases. Amer J Clin Path. 1957;28:56-60.

27. Barthel A, Schmoll D. Novel concepts in insulin regulation of hepatic gluconeogenesis. American J Physiol-Endocrin And Met. 2003;285:685-92.

28. Hundal RS, Krssak M, Dufour S, Laurent D, Lebon V, Chandramouli V, et al. Mechanism by which metformin reduces glucose production in type 2 diabetes. Diabetes. 2000;49:2063-9

29. Wiernsperger NF, Bailey CJ. The antihyperglycaemic effect of metformin Drugs. 1999;58:31-9

30. Koo SH, Flechner L, Qi L, Zhang X, Screaton RA, Jeffries S, et al. The CREB coactivator TORC2 is a key regulator of fasting glucose metabolism. Nature. 2005;437:1109.

31. Goren I, Tavor E, Goldblum A, Honigman A. Two cysteine residues in DNAbinding domain of CREB control binding to CRE and CREB-mediated gene expression. J Mol Biol. 2001;313:695-709.

32. Endo A, Sumi D, Kumagai Y. 1, 2-Naphthoquinone disrupts the function of CAMP response element-binding protein through covalent modification. Biochemical and biophysical research communications. 2007;361:243-8.

33. Adamu I, Joseph PK, Augusti KT. Hypolipidemic action of onion and garlic unsaturated oils in sucrose fed rats over a two-month period. Experientia. 1982;38:899-901.

34. Augusti KT. Hypocholesterolaemic effect of garlic, Allium sativum Linn. Ind J Exp Biol. 1977;15:489-90 


\section{SUMMARY}

- DADS showed effect on gluconeogenesis in Alloxan induced diabetic liver tissues.

- The benefits of DADS against Alloxan induced diabetic liver includes reduced activities of liver total amino acids, total ketoacids, and glucose -6- phosphatase and transaminases activities.

- Therefore, DADS holds good pharmacological potentials for treating diabetic associated hyperglycemia and related pathology.

Cite this article: Goudappala PK, Sukumar E, Yogaraje-Gowda CV, Kashinath RT. Effect of Diallyl Disulphide (DADS) on Gluconeogenesis: A Study in Isolated Alloxan Induced Diabetic Liver. Pharmacog J. 2019;11(4):777-81. 